\title{
PHARMACOLOGICAL TREATMENT FOR INSOMNIA IN PATIENTS WITH MAJOR DEPRESSIVE DISORDER
}

\section{Elisa Brietzke, Gustavo H. Vazquez, Melody J.Y. Kang \& Claudio N. Soares}

To cite this article: Elisa Brietzke, Gustavo H. Vazquez, Melody J.Y. Kang \& Claudio N. Soares (2019): PHARMACOLOGICAL TREATMENT FOR INSOMNIA IN PATIENTS WITH MAJOR DEPRESSIVE DISORDER, Expert Opinion on Pharmacotherapy, DOI: 10.1080/14656566.2019.1614562

To link to this article: https://doi.org/10.1080/14656566.2019.1614562

Accepted author version posted online: 02 May 2019.

Submit your article to this journal ๔

山 Article views: 9

View Crossmark data ¿ 
Publisher: Taylor \& Francis

Journal: Expert Opinion on Pharmacotherapy

DOI: $10.1080 / 14656566.2019 .1614562$

PHARMACOLOGICAL TREATMENT FOR INSOMNIA IN PATIENTS WITH MAJOR DEPRESSIVE DISORDER

Elisa Brietzke ${ }^{1,2}$, Gustavo H. Vazquez ${ }^{1,2}$, Melody J.Y. Kang ${ }^{3}$, Claudio N. Soares ${ }^{1}$

1. Department of Psychiatry, Queen's University School of Medicine, Kingston, ON, Canada.

2. Providence Care Hospital, Kingston, ON, Canada.

3. Center of Neuroscience Studies (CNS), Queen's University, Kingston, ON, Canada.

\section{Corresponding author}

Elisa Brietzke

752 King Street West, Postal Bag 603

Kingston, ON K7L 7X3

Tel: 6135444900 ext 73002

Fax: 6135485580

E-mail: elisa.brietzke@queensu.ca 


\section{ABSTRACT}

Introduction: Insomnia in Major Depressive Disorder (MDD) is highly prevalent and associated with increased suffering and functional impairment. Effective, evidence-based treatments for insomnia in MDD are an unmet need in clinical practice.

Areas covered: Herein, the authors provide a review of the clinical correlates, putative neurobiological mechanisms and treatment options for the management of insomnia in individuals with MDD.

Expert opinion: Sleep disturbances in MDD should be recognized as at least one of the following: 1) a domain of depressive psychopathology; 2) a consequence of rhythm disruptions; 3) a manifestation of comorbidities of sleep disturbances; 4) a manifestation of the influence of sex hormones in the brain in MDD; 5) a general medical comorbidity; and 6) a side effect of antidepressant medications. Assessment of insomnia in clinical practices is routinely performed with the use of non-structured interviews. Other methods, such as standardized questionnaires and sleep diaries, along with complementary methods such as actigraphy, and polysomnography are more scarcely applied. Smartphones and personal devices offer a promising strategy with the use of passive, long-lasting, and ecologically valid assessments despite the lack of studies specifically targeting insomnia in individuals with MDD. New therapeutic approaches are essential, including novel targets such as orexins/hypocretin and the endocannabinoid system.

Keywords: Major Depressive Disorder; Insomnia; Sleep; Mood Disorders; Hypnotic. 


\section{Article Highlights}

- Evidence-based treatments for insomnia in individuals with MDD constitute an unmet need in clinical practices.

- Insomnia in MDD should be considered as a domain of depressive psychopathology, a medical comorbidity, or an adverse event caused by psychiatric medications.

- Innovative tools for the assessment of sleep and circadian rhythms include the use of smartphones and personal devices, which can offer reliable and ecologically valid data.

- Most strategies commonly used in clinical practices are derived from secondary analyses in randomized controlled trials.

- New molecular targets, such as orexins/hypocretins circuits and cannabinoids are a promising strategy to manage insomnia in MDD. 


\section{Introduction}

Insomnia is a very common complaint both in the general population and in individuals with Major Depressive Disorder (MDD) $(1,2)$. Around $10 \%$ of the general population suffers from insomnia associated with significant consequences, such as daytime sleepiness or fatigue, reduced or lack of energy, poor concentration, memory impairment, emotional lability (e.g. irritability, anxiety, mood swings), and interpersonal difficulties (3-5). The prevalence of insomnia in individuals with MDD is much higher, with some reports suggesting that up to $90 \%$ of the patients with MDD may experience insomnia at some point of their illness trajectory $(6,7)$.

Sleep problems may vary with a variety of studies reporting difficulties in initiating sleep, a reduction in total duration of sleep, increased number and frequency of awakenings, a sensation that the sleep was not restorative enough, diurnal somnolence, or different combinations of these factors $(8,9)$. MDD is traditionally associated with terminal insomnia, although difficulties in initiating sleep may be even more frequent (10). Hypersomnia can also be found during major depressive episodes, either in isolation or in combination with insomnia (11). Thus, the link between sleep and mood disorders is complex in its clinical characterization, in its biological underpinnings, and potentially in therapeutic approaches required for its management $(12,13)$.

The extent to which the treatment of insomnia in MDD is poorly understood has led to clinical consequences such as the excessive or prolonged use of benzodiazepines (BDZ). Although useful short-term, the long-term consumption of BDZ should be restricted due to risks of abuse, dependence, falling, delirium, other cognitive dysfunctions, acute respiratory failure, car accidents, and withdrawal symptoms (14-16).

Enduring insomnia has an adverse impact of diurnal functioning and overall functional recovery, even when the severity of depressive symptoms is mitigated or even 
largely reduced (17-18). Therefore, the lack of evidence-based treatments for insomnia in individuals with MDD should be considered an unmet need in clinical practice. In order to tackle this challenge, a critical appraisal of current practices should be considered, including off-label prescription of pharmacological agents, as well as the investigation of novel agents to treat insomnia in MDD.

Although the optimum treatment of insomnia in MDD is likely multi-faceted and behavioral strategies are one of its cornerstones, the main objectives of this review are to summarize the evidence of pharmacological treatments of insomnia in MDD and discuss novel, useful approaches in research and clinical practice. The description of normal physiology of sleep is out of the scope of this review - for that, we suggest the work of Chokverty (19).

\section{Clinical Correlates of Insomnia in MDD}

\subsection{Insomnia as a domain of depressive psychopathology}

The different conceptual approaches to the symptomatic heterogeneity in depressive psychopathology have reached a new milestone in time with the launching of The NIMH Research Domain Criteria (RDoC) project. According to the RDoC framework, biological substrates of different dimensions of depression could be assessed using multiple methods of analysis, going from behavior and emotional experiences, to neural circuits, to molecules and genes (20). Although the adoption of RDoC in research of sleep and depression is still in its incipient stages, some evidence suggests that the presence and severity of insomnia in MDD could be related to a subgroup of patients with a heightened predisposition to more severe illness trajectories (Figure 1).

For example, insomnia was identified as a predictor of recurrent depressive episodes in a $\mathrm{STAR}^{*} \mathrm{D}$ data analysis (21), with insomnia during the maintenance phase of an MDD 
treatment being a significant predictor of both relapse and recurrence (21). These results are also seen in specific populations with depression, such as pregnant women with MDD (22); child and adolescents (23) and older adults (24).

Cognitive deficits in MDD also seem to be influenced by the presence and severity of sleep problems (25). It is well defined both in healthy individuals and the subjects with MDD that a proper time for sleep as well as normal sleep architecture is needed to promote memory consolidation (26). In a group of people with MDD, those with insomnia had significantly increased connectivity between the anterior medial prefrontal cortex to both the parahippocampal cortex and the hippocampal formation, compared to those without sleep disturbances. This finding supports the notion of a specific MDD phenotype with changes in the default mode network, a critical circuit for cognition (27).

Another supporting argument for insomnia to be a marker of severity of course in MDD is its association with suicidality. Insomnia has been consistently associated with suicidal ideation $(28,29)$, and is an independent predictor of suicide attempts in longitudinal studies (30). Total duration of sleep is inyersely correlated with suicide risk in patients with severe depression (31).

\subsection{Insomnia as a manifestation of the disruption of rhythms in MDD}

There is evidence that the presence of insomnia in patients with MDD could be the expression of impairments in circadian regulation of biological rhythms (Figure 1). Replicated results suggest that irregular sleep patterns could occur earlier than the emergence of a full blown depressive episode in individuals with MDD (32), opening an exciting avenue of investigation linking a set of genes involved in sleep-wake cycle regulation and behavioral manifestations of MDD. Interestingly, these new results were similar to older observations that showed interventions targeting circadian rhythm, such as sleep deprivation, having antidepressant properties (33). A recent meta-analysis including various forms of sleep 
deprivation techniques have shown antidepressant response rates between $45-50 \%$ across samples with different clinical characteristics (e.g. sex, age, medication status, criteria used to define response) (34).

In addition, the idea that MDD is a circadian rhythm illness is reinforced by mounting evidence showing that diurnal rhythmicity (sleep, temperature, mood and hormone secretion) is altered during depressive episodes (35). Mechanisms behind rhythm in MDD remain largely unknown; however, recently several studies have shown support for epigenetic and transcriptional changes in a subgroup of genes called CLOCK genes which are responsible for controlling biological rhythms (36). Disruption of normal expression of CLOCK genes was found in individuals with MDD, especially in the anterior cingulate cortex (ACC), a region critical for integration of somatic stimuli, regulation of hedonic tonus, reward behaviors, and emotional regulation (35). Interestingly, transcription of CLOCK genes may be acutely changed by sleep deprivation and by another rapid action antidepressant, intravenous ketamine (37).

Taken together, these findings suggest that the difficulties in initiating sleep could be part of a more global phenomenon of rhythm dysregulation in MDD, and possibly linked to transcriptional abnormalities in CLOCK genes. Therapies targeting this set of genes, such as ketamine, may have circadian regulation as a part of their mechanisms of action (37), and may have the potential to mitigate these problems.

\subsection{Insomnia as a manifestation of comorbid sleep disturbances in MDD}

The concomitant presence of insomnia and other sleep disturbances among MDD patients has been clearly documented $(1,38)$ (Figure 1$)$. The prevalence of sleep disturbance is higher among individuals with MDD compared to the general population (39). Obstructive sleep apnea (OSA), for example, is found in approximately $20 \%$ of individuals with MDD, 
particularly among obese and older individuals (40). The presence of OSA is a well-known risk factor for the development of depression in long-term follow-up studies (41).

Insomnia was found in around $68 \%$ of the subjects with OSA (42) and this specific comorbidity has been related to a higher risk for suicidal ideation and suicide planning in MDD (43). As OSA is not routinely assessed in psychiatric standard care, more frequent screenings and increased awareness should be promoted, especially in patients with treatment-resistant presentations and residual symptoms (44). Although the screening for OSA is not often conducted in psychiatric settings, there are simple and feasible methods to improve the detection of OSA, such as The Snoring, Tiredness, Observed apnea, High BP, BMI, Age, Neck circumference, and Male gender (STOP-Bang) Questionnaire. It is a reliable, concise, and easy-to-use screening tool, with yes/no responses and a score that ranges from 0 to 8 (45). This instrument has high sensitivity and specificity. It's sensitive for scores $\geq 3$ to detect moderate to severe OSA and severe OSA is $93 \%$ and $100 \%$, respectively. Patients with a STOP-Bang score lower than 3 are classified as low risk, whereas those with a score of 5 to 8 can be classified as high risk, for moderate to severe OSA (45). It has been largely adopted in anesthesia and surgical assessment with excellent performance in this context (46).

Another very relevant sleep disturbance in populations with MDD is restless legs syndrome (RLS), a sensory-motor condition in which the person has the sensation that they must move their legs in order to obtain relief (47). These symptoms are typically experienced in the transitions between wake and sleep, and can adversely affect sleep onset or maintenance. Several reports support the association between RLS and MDD (48-50), and the prevalence of RLS was associated with the severity of depressive symptoms in this population, with reports varying between $46-52 \%$ depending of the depression subtype (more common in depression with melancholic characteristics) (50). Although the mechanisms 
behind the association between MDD, RLS, and insomnia are still speculative, recent evidence suggest that the involvement of persistent dysregulation of inflammatory responses could play a role (51). As RLS could be a cause of insomnia in MDD, this condition should be addressed to reduce potentially harmful consequences in depression outcomes (52).

\subsection{Insomnia as a manifestation of the influence of sex hormones in the brain in MDD}

Both sleep disorders and MDD are more prevalent in women than in men. Some have speculated that the modulatory effects of sex hormones on sleep-wake behaviors and mood might contribute to heightened risk for both conditions in women. Specifically, their unique sleep expression throughout their reproductive life cycle, including premenstrual sleep disturbances, sleep problems during pregnancy, postpartum and menopausal years, may contribute (53) (Figure 1).

The interactions between sleep disorders, depression, and vasomotor symptoms among menopausal women have been a focus of mechanistic and therapeutic studies. Contrary to initial thoughts or the so-called 'domino theory', depression and insomnia in menopausal women cannot be solely explained by the presence of nocturnal vasomotor symptoms leading to a disrupted sleep $(54,55)$.

In a recent study, women undergoing estradiol withdrawal experienced more depressive symptoms in association with sleep disturbance and the number of nighttime, but not daytime, hot flashes. These results suggest that some hypoestrogenic women could be particularly susceptible to the development of menopause-associated depressive symptoms in the context of sleep disruption and reports of bothersome nighttime vasomotor symptoms (56).

\subsection{Insomnia as a manifestation of general medical comorbidity}

Different general medical comorbidities have insomnia as one of their symptoms; a condition referred to as secondary insomnia (Figure 1). Examples of these conditions are 
those suffering from chronic pain, such as migraine (57,58), orofacial pain (59), and musculoskeletal pain $(60,61)$. Overall, the data from studies using different designs suggest a bidirectional and proportional association between sleep duration and pain intensity. The prevalence of insomnia in chronic pain is especially high among women, with high intensity of pain and in the presence of anxiety symptoms (62).

Other general medical conditions commonly associated with insomnia are coronary heart disease (63), type 2 diabetes mellitus (64) and cancer (65). The division between primary versus secondary insomnia has been criticized by some authors, as it suggest that only treating the comorbid condition will automatically produce improvement of insomnia. Nevertheless, most studies suggest that both sleep and the comorbid condition should be addressed simultaneously (61).

\subsection{Insomnia as a side effect of antidepressive medications}

Several antidepressants have insomnia among their side-effects, including the most commonly prescribed serotonin selective reuptake inhibitors. In addition, other antidepressants such as dual inhibitors (venlafaxine, desvenlafaxine and duloxetine) also could cause insomnia (Figure 1). Agents such as bupropion and vilazodone (66) that are commonly prescribed alone or in association can also compromise sleep in the beginning of the night. It is thought that activation of 5HT2, dopaminergic, and noradrenergic agents would be responsible for this side-effect. A summary of the potential of different antidepressants in producing insomnia could be found in Table 1.

This side effect is clinically significant for several reasons. First, it may be associated with a prolonged period of time required to achieve response. Data from two samples, including one from Sequenced Treatment Alternatives to Relieve Depression (STAR*D) suggest that late responders to citalopram also reported higher levels of antidepressant induced initial insomnia, compared to early responders, suggesting that antidepressant- 
induced insomnia could play a role in delayed recovery in MDD (67). In addition, there is a possibility of patients adopting unhealthy ways to cope with insomnia, such as alcohol use (68).

A significant gap of the literature on this topic is the lack of systematic investigation on the direct comparison between agents regarding this side-effect. In addition, the correlation between improvement of insomnia and production of daytime sleepiness was not completely investigated (69). Another limitation is the variety of heterogeneous methods to assess presence and severity of treatment emergent insomnia in clinical trials (70).

Regarding the approach of antidepressant-induced insomnia, one of the most investigated strategies is to add on hypnotic agents such as zolpidem. One randomized controlled trial investigates adjunctive zolpidem for patients with MDD and persistent insomnia in the presence of effective and stable treatment with SSRIs. Compared to placebo, zolpidem at a dose of $10 \mathrm{mg}$ was associated with improvement of sleep quality, sleep duration, and reduced number of awakenings (71).

\section{Assessment of Insomnia in MDD}

A detailed assessment of sleep in MDD can be obtained by the use of complementary methods, such as polysomnography (PSG) and actigraphy. The polysomnography provides the assessment of sleep architecture through the analysis of variables extracted from different physiological parameters from the brain (EEG), muscles (EMG), and eye movements. Typically, individuals with MDD exhibit increased sleep latency, number, and duration of awakenings from sleep expressed as increased wake after sleep onset (WASO) time, decreased sleep efficiency, and early morning awakenings (72). The association of early morning awakenings and abnormal distributions of REM sleep is also typical of major depressive episodes, especially those with melancholic characteristics (73). Actigraphy 
records wake-sleep cycles over several days, weeks or months which this enables the recording of both periods with Zeitgebers (i.e., constraints that influence the person's rhythms, such as work, physical activity of meal times) and periods without (74). Actigraphy is a useful and validated tool to assess psychomotor activity and sleep-wake rhythms in MDD $(75,76)$. Combined with PSG, actigraphy provides objective assessments of sleep and rhythms, helping to determine biological validity in behavior-based parameters including MDD subtypes, severity of symptoms across different domains of depressive psychopathology, and prediction of relapse (76-78)

Although time-consuming and relatively expensive, objective assessments with the use of PSG and actigraphy in MDD have recently shown to be helpful in predicting critical outcomes in MDD. In a recent study by Bernet et al. (79), the presence of suicidal ideation in subjects with treatment resistant MDD was associated with less NREM Stage 4 sleep, and higher nocturnal wakefulness, regardless of severity of symptoms. These results reinforced the role of sleep in the suicidality risk, particularly in treatment-resistant depression, when such risks may be substantial.

One alternative to objectively assess sleep and circadian rhythms in individuals with MDD is through the passive gathering of data via wearable devices (80). Given the ubiquity and popularity of mobile apps, this strategy may be used to effectively obtain reliable and ecologically valid information on sleep patterns among individuals with MDD. Such practices, if proven reliable and reproducible, could be instrumental for mental health providers to better determine indicators of relapse or recurrence, and eventually offer selfregulatory strategies (81). However, wearable devices for monitoring sleep through movement and light sensors have yet to be successfully validated against gold standard methods such as PSG and actigraphy, creating opportunities for further development and cooperation between mood/sleep researchers and technology developers (82). 
These objective criteria are also helpful in the assessment of sleep disruption in patients reporting poor sleep quality. It should be noted that the self-reported sleep onset, duration and quality do not always correspond to objective measures. For example, it could be important to identify patient-perceived insomnia (e.g. difficulty going to sleep at night or remain sleeping) which may co-occur with a long duration of sleep. It is possible that a patient with this profile report high scores in both insomnia and hypersomnia. Indeed, the association of insomnia and hypersomnia is not uncommon in MDD (6).

\section{Management of Insomnia in MDD}

Some antidepressants with sleep promoting properties have been used in clinical care of patients with MDD aiming to treat, with the same drug, both sleep and other domains of depressive psychopathology. The prescription of these agents is supported by clinical experience, as there are results showing superiority of these agents over others. For example, one study with patients with chronic or recurrent MDD randomized to receive (1) escitalopram + placebo, (2) bupropion-sustained-release + escitalopram, or (3) venlafaxine-extended-release + mirtazapine for 28 weeks, did not find a benefit of adding mirtazapine to the medication regimen to improve sleep compared to the other arms (83).

Some of the most commonly adopted agents are described below:

\subsection{Agomelatine}

Agomelatine is a dual action agent with pharmacological affinity for MT1 and MT2 melatonin receptors and 5-HT2C antagonist properties. Randomized controlled trials suggest simultaneous efficacy of agomelatine for treating depressive symptoms and sleep impairments (84). In direct comparisons, standard SSRIs such as escitalopram have shown to be superior than agomelatine to promote early onset responses and higher remission rates; notwithstanding, agomelatine could be considered in specific cases in which insomnia is a 
predominant symptom (85). This medication could also be used for patients who experience insomnia as a side-effect of SSRIs (86) or in cases when the use of sedative/hypnotic medications are not recommended (84).

\subsection{Mirtazapine}

Mirtazapine is a tetracyclic piperazinoazepine, with a peculiar structure that distinguishes it from any other antidepressant currently on the market. Mirtazapine is considered a good choice for patients with MDD and insomnia, as sedation is one of its main side-effects (87). Most of its use in primary insomnia is off-label, although there is some evidence supporting low doses of mirtazapine $(7.5 \mathrm{mg})$ as a hypnotic, with good tolerability and positive effects on sleep quantity, efficiency $(88,89)$, and functioning (90).

\subsection{Trazodone}

Trazodone was approved by FDA as an antidepressant, despite the scarcity of clinical trials as a hypnotic. Trazadone is used by around 1\% of the USA population to manage insomnia (91) - usually in doses between 25 and $100 \mathrm{mg}$.

\section{Expert Opinion}

Treatment of insomnia in MDD is challenging, reflecting its heterogeneity in pathophysiology and clinical presentations. Considering that insomnia is related to relapse and recurrence of depressive episodes as well as severe outcomes such as suicidality, more effective treatments for insomnia in MDD are warranted. For that, some alternatives should be considered.

\subsection{Key Findings in the Field}

A compelling body of evidence supports the notion that insomnia in MDD should not be considered merely as a depressive symptom; instead, insomnia could be understood or characterized as a marker of risk for severity of course, relapse/recurrence, treatment 
resistance, and functional impairment. The proper assessment and treatment of insomnia in MDD has the potential not only to provide relief to patients, but also to modify the course of the illness. In spite of this, tolerable and effective agents to treat insomnia are not widely available for patients with depression. Investigation of new therapeutic targets are required.

Promising new tools for clinical assessment and diagnosis of insomnia are emerging and require further attention. Among those, the use of new technologies for the evaluation of sleep patterns and other biological rhythms may lead to better accuracy in the diagnosis of sleep problems and reduction in the costs incurred for the acquisition of more objective sleep parameters. Repurposing existing drugs that were originally developed for other indications could be a valid approach in the next few years, while new biological targets are pursued.

\subsection{Limitations of the Literature}

Although several trials consider insomnia as a secondary outcome in the treatment of MDD, very few studies were designed specifically to address insomnia in this population (92). One rare example is a recent RCT that examined the effects of adjunctive treatment with brexpiprazole - the new second generation antipsychotic - on patients with MDD who presented with unsatisfactory responses to conventional antidepressants. In this trial, add-on brexpiprazole was successful in improving insomnia, diurnal somnolence, and overall functioning (93). A summary of the limitations of the literature is described in Table 2.

\subsection{Future Perspectives}

Existent evidence suggests that depressive psychopathology extends far beyond monoaminergic abnormalities; hence, new neurotransmitters systems remain as an underexplored pathway in the treatment of insomnia in MDD. The orexins/hypocretins system is one of these putative pathways. Orexins are neuropeptides which act in the brain 
through binding with two different receptors, OX1R and OX2R, which activate a cell cascade mediated by a G-protein (94). Data suggest the involvement of orexins/hypocretins in multiple physiological functions including feeding, addiction, reward and motivation, anxiety and depression, cardiovascular regulation, pain, migraine, and neuroendocrine regulation including reproduction. Their actions have been shown to be particularly relevant to promote the transition from awake to sleep $(95,96)$. Pharmacological orexin antagonism is linked to the promotion of sleep, and the so-called dual orexin antagonists (blockers of OX1R and OX2R) are beneficial in the treatment of insomnia, promoting both REM and non-REM sleep. In addition, emerging evidence suggest that orexin antagonism could have antidepressant properties, despite some mixed results from animal studies and in humans (9799).

Another promising target is the endocannabinoid system, as both endocannabinoid levels and their receptors exhibit circadian oscillations (100). As of now, there is no clear benefit of cannabidiol for insomnia in MDD, although there have been reports of improvement of diurnal somnolence and sleep quality (101). The few studies in humans are corroborated by a more robust animal research suggesting a potential effect of cannabidiol and synthetic cannabinoids - such as nabilone in improvement of sleep (102).

Finally, inflammation has also been considered as a significant target for insomnia in MDD. Specifically, insomnia has been associated with chronic low grade inflammatory activation, evident by the detection of a peripheral increase of inflammatory mediators such as C-reactive Protein (CRP), Tumor Necrosis factor-alpha (TNF-alpha) and Interleukin-6 (IL6) (103). These biomarkers were also largely demonstrated and reproduced in studies comparing individuals with MDD and healthy controls $(104,105)$. Although the effect of anti-inflammatory medications has not been systematically investigated in the treatment of MDD-associated insomnia, it is possible that the subgroup of patients with MDD and 
insomnia represents a specific "inflammatory" phenotype, which could be useful in stratification of subjects for future clinical trials targeting inflammation in MDD (106).

\section{Funding:}

This manuscript was not funded.

\section{Declaration of Interest}

E Brietzke has received speaker's and advisory board membership honoraria from Daiichi Sankyo. She has also received research grant support from the São Paulo Research Foundation (FAPESP), the National Council for Scientific and Technological Development (CNPq) and the Coordination for the Improvement of Higher Education Personnel (CAPES). She is also the recipient of the L'Oréal For Women in Science Award. CN Soares has received research grants from the Ontario Brain Institute (OBI) and the Ontario Research Fund for Excellence (ORF-RE). He has also served as a consultant for Lundbeck, Sunovion, Bayer, Pfizer Inc and Otsuka. The authors have no other relevant affiliations or financial involvement with any organization or entity with a financial interest in or financial conflict with the subject matter or materials discussed in the manuscript apart from those disclosed.

\section{Reviewer Disclosures:}

Peer reviewers on this manuscript have no relevant financial or other relationships to disclose. 


\section{References}

1. Taylor SS, Hughes JM, Coffman CJ, Jeffreys AS, Ulmer CS, Oddone EZ, Bosworth HB, Yancy WS Jr, Allen KD. Prevalence of and characteristics associated with insomnia and obstructive sleep apnea among veterans with knee and hip osteoarthritis. BMC Musculoskelet Disord. 2018 Mar 9;19(1):79.

2. Jordan P, Shedden-Mora MC, Löwe B. Predicting suicidal ideation in primary care: An approach to identify easily assessable key variables. Gen Hosp Psychiatry. 2018 Mar - Apr;51:106-111.

3. Shochat T, Cohen-Zion M, Tzischinsky O. Functional consequences of inadequate sleep in adolescents: a systematic review. Sleep Med Rev. 2014 Feb;18(1):75-87.

4. Chung KF, Yeung WF, Ho FY, Ho LM, Yung KP, Yu BY, Kwok CW. Predictors of daytime consequences of insomnia: the roles of quantitative criteria and nonrestorative sleep. Psychopathology. 2018;51(4):262-268.

5. Shekleton JA, Flynn-Evans EE, Miller B, Epstein LJ, Kirsch D, Brogna LA, Burke LM, Bremer E, Murray JM, Gehrman P, Lockley SW, Rajaratnam SM. Neurobehavioral performance impairment in insomnia: relationships with selfreported sleep and daytime functioning. Sleep. 2014 Jan 1;37(1):107-16.

6. Soehner AM, Kaplan KA, Harvey AG. Prevalence and clinical correlates of cooccurring insomnia and hypersomnia symptoms in depression. $\mathrm{J}$ Affect Disord. 2014;167:93-7.

7. Seow LS, Subramaniam M, Abdin E, Vaingankar JA, Chong SA. Sleep disturbance among people with major depressive disorders (MDD) in Singapore. J Ment Health. 2016 Dec;25(6):492-499.

8. Sivertsen B, Vedaa Ø, Harvey AG, Glozier N, Pallesen S, Aarø LE, Lønning KJ, Hysing M. Sleep patterns and insomnia in young adults: A national survey of Norwegian university students. J Sleep Res. 2018 Dec 4:e12790.

9. Pigeon WR, Bishop TM, Krueger KM. Insomnia as a precipitating factor in new onset mental illness: a systematic review of recent findings. Curr Psychiatry Rep. 2017 Aug;19(8):44.

10. Geoffroy PA, Hoertel N, Etain B, Bellivier F, Delorme R, Limosin F2, Peyre H. Insomnia and hypersomnia in major depressive episode: Prevalence, sociodemographic characteristics and psychiatric comorbidity in a population-based study. J Affect Disord. 2018 Jan 15;226:132-141.

* Useful discussion about the co-existence of insomnia and hypersomnia in MDD. 
11. Rumble ME, White KH, Benca RM. Sleep disturbances in mood disorders. Psychiatr Clin North Am. 2015 Dec;38(4):743-59.

12. Tempaku P, Hirotsu C, Mazzotti D, Xavier G, Maurya P, Brietzke E, Belangero S, Poyares D, Bittencourt L, Tufik S. Long sleep duration, insomnia, and insomnia with short objective sleep duration are independently associated with short telomere length. J Clin Sleep Med. 2018 Nov 29. pii: jc-18-00113.

13. Grigolon RB, Trevizol AP, Cerqueira RO, Lee Y, Mansur RB, McIntyre RS, Brietzke E. Hypersomnia and bipolar disorder: a systematic review and proportion metaanalysis. J Affect Disord 2019 (in press).

14. Sanyal C, Asbridge M, Kisely S, Sketris I, Andreou P. The utilization of antidepressants and benzodiazepines among people with major depression in Canada. Can J Psychiatry. 2011 Nov;56(11):667-76.

15. Manthey L1, Lohbeck M, Giltay EJ, van Veena T, Zitman FG, Penninx BW. Correlates of benzodiazepine dependence in the Netherlands Study of Depression and Anxiety. Addiction. 2012 Dec;107(12):2173-82.

16. Kurko TA, Saastamoinen LK, Tähkäpää S, Tuulio-Henriksson A, Taiminen T, Tiihonen J, Airaksinen MS, Hietala J. Long-term use of benzodiazepines: Definitions, prevalence and usage patterns - a systematic review of register-based studies. Eur Psychiatry. 2015 Nov;30(8):1037-47.

17. O'Brien EM, Chelminski I, Young D, Dalrymple K, Hrabosky J, Zimmerman M. Severe insomnia is associated with more severe presentation and greater functional deficits in depression. J Psychiatr Res. 2011 Aug;45(8):1101-5.

18. Xiao L, Feng L, Zhu XQ, Feng Y, Wu WY, Ungvari GS, Ng CH, Xiang YT, Wang G. Comparison of residual depressive symptoms and functional impairment between fully and partially remitted patients with major depressive disorder: a multicenter study. Psychiatry Res. 2018 Mar;261:547-553.

19. Chokroverty S. Overview of Normal Sleep. In: Chokroverty S. Sleep Disorders. Springer, New York, NY, 2017.

20. Woody ML, Gibb BE. Integrating NIMH Research Domain Criteria (RDoC) into depression research. Curr Opin Psychol. 2015 Aug;4:6-12.

** Fundamental study about application of RDoC to MDD research.

21. Sakurai H, Suzuki T, Yoshimura K, Mimura M, Uchida H. Predicting relapse with individual residual symptoms in major depressive disorder: a reanalysis of the STAR*D data. Psychopharmacology. 2017 Aug;234(16):2453-2461. 
** Important study reporting STAR*D data on recurrence and relapse.

22. Suri R, Stowe ZN, Cohen LS, Newport DJ, Burt VK, Aquino-Elias AR, Knight BT, Mintz J, Altshuler LL. Prospective longitudinal study of predictors of postpartumonset depression in women with a history of Major Depressive Disorder. J Clin Psychiatry. 2017 Sep/Oct; 78(8):1110-1116.

23. Nunes ML, Bruni O. Insomnia in childhood and adolescence: clinical aspects, diagnosis, and therapeutic approach. J Pediatr. 2015 Nov-Dec;91(6 Suppl 1):S26-35.

24. Gulia KK, Kumar VM. Sleep disorders in the elderly: a growing challenge. Psychogeriatrics. 2018;18(3):155-165.

25. Pan Z, Park C, Brietzke E, Zuckerman H, Rong C, Mansur RB, Fus D, Subramaniapillai M, Lee Y, McIntyre RS. Cognitive impairment in major depressive disorder. CNS Spectr. 2018 (in press).

26. Nishida M, Nakashima Y, Nishikawa T. Slow sleep spindle and procedural memory consolidation in patients with major depressive disorder. Nat Sci Sleep. 2016 Jan 28;8:63-72.

27. McKinnon AC, Hickie IB, Scott J, Duffy SL, Norrie L, Terpening Z, Grunstein RR, Lagopoulos J, Batchelor J, Lewis SJG, Shine JM, Naismith SL. Current sleep disturbance in older people with a lifetime history of depression is associated with increased connectivity in the Default Mode Network. J Affect Disord. 2018 Mar 15;229:85-94.

28. Fang X1, Zhang C2, Wu Z1, Peng D1, Xia W, Xu J, Wang C, Cui L, Huang J, Fang Y. The association between somatic symptoms and suicidal ideation in Chinese firstepisode major depressive disorder. J Affect Disord. 2018 Oct 17;245:17-21.

29. Don Richardson J, King L, St Cyr K, Shnaider P, Roth ML, Ketcheson F, Balderson K, Elhai JD. Depression and the relationship between sleep disturbances, nightmares, and suicidal ideation in treatment-seeking Canadian Armed Forces members and veterans. BMC Psychiatry. 2018 Jun 19;18(1):204.

30. Eikelenboom M, Beekman ATF, Penninx BWJH, Smit JH. A 6-year longitudinal study of predictors for suicide attempts in major depressive disorder. Psychol Med. 2018 (in press).

31. Michaels MS, Balthrop T, Nadorff MR, Joiner TE. Total sleep time as a predictor of suicidal behaviour. J Sleep Res. 2017 Dec;26(6):732-738.

* Article describing association between insomnia and suicidal behavior in MDD. 
32. Breslau N, Roth T, Rosenthal L, Andreski P. Sleep disturbance and psychiatric disorders: a longitudinal epidemiological study of young adults. Biol Psychiatry. 1996 Mar 15;39(6):411-8.

33. Wu JC, Bunney WE. The biological basis of an antidepressant response to sleep deprivation and relapse: review and hypothesis. Am J Psychiatry. 1990 Jan;147(1):1421.

34. Boland EM, Rao H, Dinges DF, Smith RV, Goel N, Detre JA, Basner M, Sheline YI, Thase ME, Gehrman PR. Meta-analysis of the antidepressant effects of acute sleep deprivation. J Clin Psychiatry. 2017 Sep/Oct;78(8):e1020-e1034.

35. Bunney BG, Li JZ, Walsh DM, Stein R, Vawter MP, Cartagena P, Barchas JD, Schatzberg AF, Myers RM, Watson SJ, Akil H, Bunney WE. Circadian dysregulation of clock genes: clues to rapid treatments in major depressive disorder. Mol Psychiatry. $2015 \mathrm{Feb} ; 20(1): 48-55$.

36. Charrier A, Olliac B, Roubertoux P, Tordjman S. Clock genes and altered sleep-wake rhythms: their role in the development of psychiatric disorders. Int J Mol Sci. 2017 Apr 29;18(5). pii: E938.

37. Orozco-Solis R, Montellier E, Aguilar-Arnal L, Sato S, Vawter MP, Bunney BG, Bunney WE, Sassone-Corsi P. A Circadian Genomic Signature Common to Ketamine and Sleep Deprivation in the Anterior Cingulate Cortex. Biol Psychiatry. 2017 Sep $1 ; 82(5): 351-360$.

38. Sun X, Zheng B, Lv J, Guo Y, Bian Z, Yang L, Chen Y, Fu Z, Guo H, Liang P, Chen Z, Chen J, Li L, Yu C; China Kadoorie Biobank (CKB) Collaborative Group. Sleep behavior and depression: findings from the China Kadoorie Biobank of 0.5 million Chinese adults. J Affect Disord. 2018 Mar 15;229:120-124.

39. Lang CJ, Appleton SL, Vakulin A, McEvoy RD, Wittert GA, Martin SA, Catcheside PG, Antic NA, Lack L, Adams RJ. Co-morbid OSA and insomnia increases depression prevalence and severity in men. Respirology. 2017 Oct;22(7):1407-1415.

40. Stubbs B, Vancampfort D, Veronese N, Solmi M, Gaughran F, Manu P, Rosenbaum S, De Hert M, Fornaro M. The prevalence and predictors of obstructive sleep apnea in major depressive disorder, bipolar disorder and schizophrenia: A systematic review and meta-analysis. J Affect Disord. 2016 Jun;197:259-67.

41. Chen YH, Keller JK, Kang JH, Hsieh HJ, Lin HC. Obstructive sleep apnea and the subsequent risk of depressive disorder: a population-based follow-up study. J Clin Sleep Med. 2013 May 15;9(5):417-23. 
42. Lichstein KL, Justin Thomas S, Woosley JA, Geyer JD. Co-occurring insomnia and obstructive sleep apnea. Sleep Med. 2013 Sep; 14(9):824-9.

43. Bishop TM, Ashrafioun L, Pigeon WR. The association between sleep apnea and suicidal thought and behavior: an analysis of national survey data. J Clin Psychiatry. 2018 Jan/Feb;79(1). pii: 17m11480. doi: 10.4088/JCP.17m11480.

44. Hobzova M, Prasko J, Vanek J, Ociskova M, Genzor S, Holubova M, Grambal A, Latalova K. Depression and obstructive sleep apnea. Neuro Endocrinol Lett. 2017 Oct;38(5):343-352.

45. Chung F, Abdullah HR, Liao P. STOP-Bang Questionnaire: A Practical Approach to Screen for Obstructive Sleep Apnea. Chest. 2016 Mar;149(3):631-8.

46. Nagappa M, Liao P, Wong J, Auckley D, Ramachandran SK, Memtsoudis S, Mokhlesi B, Chung F. Validation of the STOP-Bang Questionnaire as a Screening Tool for Obstructive Sleep Apnea among Different Populations: A Systematic Review and Meta-Analysis. PLoS One. 2015 Dec 14;10(12):e0143697.

47. Venkateshiah SB, Ioachimescu OC. Restless legs syndrome. Crit Care Clin. 2015 Jul;31(3):459-72.

48. Koo BB, Blackwell T, Lee HB, Stone KL, Louis ED, Redline S; Osteoporotic Fractures in Men (MrOS) Study Group. Restless legs syndrome and depression: effect mediation by disturbed sleep and periodic limb movements. Am J Geriatr Psychiatry. 2016 Nov;24(11):1105-1116.

49. Sarberg M, Bladh M, Svanborg E, Josefsson A. Postpartum depressive symptoms and its association to daytime sleepiness and restless legs during pregnancy. BMC Pregnancy Childbirth. 2016 Jun 6;16(1):137.

50. Auvinen P, Mäntyselkä P, Koponen H, Kautiainen H, Korniloff K, Ahonen T, Vanhala M. Prevalence of restless legs symptoms according to depressive symptoms and depression type: a cross-sectional study. Nord J Psychiatry. 2018a Jan;72(1):5156.

51. Auvinen P, Mäntyselkä P, Koponen H, Kautiainen H, Korniloff K, Ahonen T, Vanhala M. Elevation of tumor necrosis factor alpha levels is associated with restless legs symptoms in clinically depressed patients. J Psychosom Res. 2018b Dec;115:1-5.

52. Becker PM, Sharon D. Mood disorders in restless legs syndrome (Willis-Ekbom disease). J Clin Psychiatry. 2014 Jul;75(7):e679-94.

53. Soares CN, Murray BJ. Sleep disorders in women: clinical evidence and treatment strategies. Psychiatr Clin North Am. 2006;29(4):1095-113. 
54. Joffe H, Soares CN, Thurston RC, White DP, Cohen LS, Hall JE. Depression is associated with worse objectively and subjectively measured sleep, but not more frequent awakenings, in women with vasomotor symptoms. Menopause. 2009;16(4):671-9.

55. Soares CN, Joffe H, Rubens R, Caron J, Roth T, Cohen L. Eszopiclone in patients with insomnia during perimenopause and early postmenopause: a randomized controlled trial. Obstet Gynecol. 2006;108(6):1402-10.

56. Joffe H, Crawford SL, Freeman MP, White DP, Bianchi MT, Kim S, Economou N, Camuso J, Hall JE, Cohen LS. Independent contributions of nocturnal hot flashes and sleep disturbance to depression in estrogen-deprived women. J Clin Endocrinol Metab. 2016;101(10):3847-3855.

57. Kim SJ, Han KT, Jang SY, Yoo KB, Kim SJ. The association between migraine and types of sleep disorder. Int J Environ Res Public Health. 2018 Nov 26;15(12).

58. Buse DC, Rains JC, Pavlovic JM, Fanning KM, Reed ML, Manack Adams A, Lipton RB. Sleep disorders among people with migraine: results from the Chronic Migraine Epidemiology and Outcomes (CaMEO) Study. Headache. 2019 Jan;59(1):32-45.

59. Almoznino G, Haviv Y, Sharav Y, Benoliel R. An update of management of insomnia in patients with chronic orofacial pain. Oral Dis. 2017 Nov;23(8):10431051.

60. Generaal E, Vogelzangs N, Penninx BW, Dekker J. Insomnia, sleep duration, depressive symptoms, and the onset of chronic multisite musculoskeletal pain. Sleep. 2017 Jan 1;40(1).

61. Frange C, Hachul H, Hirotsu C, Tufik S, Andersen ML. Temporal analysis of chronic musculoskeletal pain and sleep in postmenopausal women. J Clin Sleep Med. 2019 Feb 15;15(2):223-234.

62. Alföldi P, Dragioti E, Wiklund T, Gerdle B. Spreading of pain and insomnia in patients with chronic pain: results from a national quality registry (SQRP). J Rehabil Med. 2017 Jan 19;49(1):63-70.

63. Zhuang J, Zhan Y, Zhang F, Tang Z, Wang J, Sun Y, Ding R, Hu D, Yu J. Selfreported insomnia and coronary heart disease in the elderly. Clin Exp Hypertens. 2016;38(1):51-5. 
64. Tan X, van Egmond L, Chapman CD, Cedernaes J, Benedict C. Aiding sleep in type 2 diabetes: therapeutic considerations. Lancet Diabetes Endocrinol. 2018 Jan;6(1):6068.

65. Sen A, Opdahl S, Strand LB, Vatten LJ, Laugsand LE, Janszky I. Insomnia and the Risk of Breast Cancer: The HUNT Study. Psychosom Med. 2017 May;79(4):461-468.

66. Shi L, Wang J, Xu S, Lu Y. Efficacy and tolerability of vilazodone for major depressive disorder: evidence from phase III/IV randomized controlled trials. Drug Des Devel Ther. 2016 Nov 25;10:3899-3907.

67. Fabbri C, Marsano A, Balestri M, De Ronchi D, Serretti A.Clinical features and drug induced side effects in early versus late antidepressant responders. J Psychiatr Res. 2013 Oct;47(10):1309-18.

68. Kikuchi T, Suzuki T, Uchida H, Watanabe K, Mimura M. Coping strategies for antidepressant side effects: an Internet survey. J Affect Disord. 2012 Dec 20;143(13):89-94.

69. Liu Y, Xu X, Dong M, Jia S, Wei Y. Treatment of insomnia with tricyclic antidepressants: a meta-analysis of polysomnographic randomized controlled trials. Sleep Med. 2017 Jun;34:126-133.

70. Uher R, Farmer A, Henigsberg N, Rietschel M, Mors O, Maier W, Kozel D, Hauser J, Souery D, Placentino A, Strohmaier J, Perroud N, Zobel A, Rajewska-Rager A, Dernovsek MZ, Larsen ER, Kalember P, Giovannini C, Barreto M, McGuffin P, Aitchison KJ. Adverse reactions to antidepressants. $\mathrm{Br}$ J Psychiatry. 2009 Sep;195(3):202-10.

71. Asnis GM, Chakraburtty A, DuBoff EA, Krystal A, Londborg PD, Rosenberg R, Roth-Schechter B, Scharf MB, Walsh JK. Zolpidem for persistent insomnia in SSRI-treated depressed patients. J Clin Psychiatry. 1999 Oct;60(10):668-76

72. Wichniak A, Wierzbicka A, Walęcka M, Jernajczyk W. Effects of antidepressants on sleep. Curr Psychiatry Rep. 2017 Aug 9;19(9):63.

73. Wichniak A, Wierzbicka A, Jernajczyk W. Sleep as a biomarker for depression. Int Rev Psychiatry. 2013 Oct; 25(5):632-45.

74. Delaplace R, Garny de La Rivière S, Bon Saint Come M, Lahaye H, Popov I, Rey N, Visticot A, Guilé JM. Sleep and disruptive mood dysregulation disorder: A pilot actigraphy study. Arch Pediatr. 2018 Jun 14. pii: S0929-693X(18)30109-X. 
75. Averill IR, Crowe M, Frampton CM, Beaglehole B, Lacey CJ, Jordan J, Wilson LD, Douglas KM, Porter RJ. Clinical response to treatment in inpatients with depression correlates with changes in activity levels and psychomotor speed. Aust N Z J Psychiatry. $2018 \mathrm{Jul} ; 52(7): 652-659$.

76. van Diermen L, Schrijvers D, Cools O, Birkenhäger TK, Fransen E, Sabbe BGC. Distinguishing subgroups based on psychomotor functioning among patients with Major Depressive Disorder. Neuropsychobiology. 2017;76(4):199-208.

77. DiNapoli EA, Gebara MA, Kho T, Butters MA, Gildengers AG, Albert SM, Dew MA, Erickson KI, Reynolds CF 3rd, Karp JF. Subjective-objective sleep discrepancy in older adults with MCI and subsyndromal depression. Geriatr Psychiatry Neurol. 2017 Nov;30(6):316-323.

78. Krane-Gartiser K, Vaaler AE, Fasmer OB, Sørensen K, Morken G, Scott J. Variability of activity patterns across mood disorders and time of day. BMC Psychiatry. 2017 Dec 19;17(1):404.

79. Bernert RA, Luckenbaugh DA, Duncan WC, Iwata NG, Ballard ED, Zarate CA. Sleep architecture parameters as a putative biomarker of suicidal ideation in treatmentresistant depression. J Affect Disord. 2017 Jan 15;208:309-315.

80. Bourla A, Ferreri F, Ogorzelec L, Guinchard C, Mouchabac S. Assessment of mood disorders by passive data gathering: The concept of digital phenotype versus psychiatrist's professional culture. Encephale. 2018 Apr;44(2):168-175.

81. Lorenz CP1, Williams AJ. Sleep apps: what role do they play in clinical medicine? Curr Opin Pulm Med. 2017 Nov;23(6):512-516.

82. Paré G, Leaver C, Bourget C. Diffusion of the Digital Health Self-Tracking Movement in Canada: Results of a National Survey. J Med Internet Res. 2018 May 2;20(5):e177.

83. Sung SC, Wisniewski SR, Luther JF, Trivedi MH, Rush AJ; COMED Study Team. Pre-treatment insomnia as a predictor of single and combination antidepressant outcomes: a CO-MED report. J Affect Disord. 2015 Mar 15;174:157-64.

84. Srinivasan V, Brzezinski A, Pandi-Perumal SR, Spence DW, Cardinali DP, Brown GM. Melatonin agonists in primary insomnia and depression-associated insomnia: are they superior to sedative-hypnotics? Prog Neuropsychopharmacol Biol Psychiatry. 2011 Jun 1;35(4):913-23. 
85. Urade CS, Mahakalkar SM, Tiple PG. A comparative study of the clinical efficacy and safety of agomelatine with escitalopram in major depressive disorder patients: A randomized, parallel-group, phase IV study. J Pharmacol Pharmacother. 2015 OctDec;6(4):198-203.

86. Alberti S, Chiesa A, Andrisano C, Serretti A. Insomnia and somnolence associated with second-generation antidepressants during the treatment of major depression: a meta-analysis. J Clin Psychopharmacol. 2015 Jun;35(3):296-303.

87. Burrows GD, Kremer CM. Mirtazapine: clinical advantages in the treatment of depression. J Clin Psychopharmacol. 1997;17:34S-39S.

88. Karsten J, Hagenauw LA, Kamphuis J, Lancel M. Low doses of mirtazapine or quetiapine for transient insomnia: a randomised, double-blind, cross-over, placebocontrolled trial. J Psychopharmacol. 2017 Mar;31(3):327-337.

89. Rothschild-Fuentes B, Roche A, Jiménez-Genchi A, Sánchez-Ferrer JC, Fresan A, Muñoz-Delgado J. Effects of mirtazapine on the sleep wake rhythm of geriatric patients with major depression: an exploratory study with actigraphy. Pharmacopsychiatry. 2013 Mar;46(2):59-62.

90. Shen J, Moller HJ, Wang X, Chung SA, Shapiro GK, Li X, Shapiro CM. Mirtazapine, a sedating antidepressant, and improved driving safety in patients with major depressive disorder: a prospective, randomized trial of 28 patients. J Clin Psychiatry. 2009 Mar;70(3):370-7.

91. Bertisch SM, Herzig SJ, Winkelman JW, Buettner C. National use of prescription medications for insomnia: NHANES 1999-2010. Sleep 2014;37:343-349.

92. Liguori C, Ferini-Strambi L, Izzi F, Mari L, Manfredi N, D'Elia A, Mercuri NB, Placidi F. Preliminary evidence that vortioxetine may improve sleep quality in depressed patients with insomnia: a retrospective questionnaire analysis. Br J Clin Pharmacol. 2018 (in press).

93. Krystal AD, Mittoux A, Meisels P, Baker RA. Effects of adjunctive brexpiprazole on sleep disturbances in patients with major depressive disorder: an open-label, flexibledose, exploratory study. Prim Care Companion CNS Disord. 2016 Sep 8;18(5).

94. Peyron C, Kilduff TS. Mapping the hypocretin/orexin neuronal system: an unexpectedly productive journey. J Neurosci. 2017 Mar 1;37(9):2268-2272.

95. Mieda M. The roles of orexins in sleep/wake regulation. Neurosci Res. 2017 May;118:56-65. 
96. Schwartz MD, Kilduff TS. The neurobiology of sleep and wakefulness. Psychiatr Clin North Am. 2015 Dec;38(4):615-44.

97. Coleman PJ, Gotter AL, Herring WJ, Winrow CJ, Renger JJ. The discovery of suvorexant, the first orexin receptor drug for insomnia. Annu Rev Pharmacol Toxicol. 2017 Jan 6;57:509-533.

98. Winrow CJ, Renger JJ. Discovery and development of orexin receptor antagonists as therapeutics for insomnia. Br J Pharmacol. 2014 Jan;171(2):283-93.

99. Nollet M, Leman S. Role of orexin in the pathophysiology of depression: potential for pharmacological intervention. CNS Drugs. 2013 Jun;27(6):411-22.

100. Murillo-Rodriguez E, Poot-Ake A, Arias-Carrion O, Pacheco-Pantoja E, Fuente-Ortegon Ade L, Arankowsky-Sandoval G. The emerging role of the endocannabinoid system in the sleep-wake cycle modulation. Cent Nerv Syst Agents Med Chem. 2011 Sep 1;11(3):189-96.

101. Babson KA, Sottile J, Morabito D. Cannabis, cannabinoids, and sleep: a review of the literature. Curr Psychiatry Rep. 2017 Apr;19(4):23.

102. Hsiao YT, Yi PL, Li CL, Chang FC. Effect of cannabidiol on sleep disruption induced by the repeated combination tests consisting of open field and elevated plusmaze in rats. Neuropharmacology. 2012 Jan;62(1):373-84.

103. Irwin MR, Piber D. Insomnia and inflammation: a two hit model of depression risk and prevention. World Psychiatry. 2018 Oct;17(3):359-361.

104. Shariq AS, Brietzke E, Rosenblat JD, Barendra V, Pan Z, McIntyre RS. Targeting cytokines in reduction of depressive symptoms: A comprehensive review. Prog Neuropsychopharmacol Biol Psychiatry. 2018 Apr 20;83:86-91.

105. Maes M, Noto C, Brietzke E. Omics-based depression and inflammation research. Braz J Psychiatry. 2015 Jan-Mar;37(1):1-2.

106. Noto C, Rizzo LB, Mansur RB, McIntyre RS, Maes M, Brietzke E. Targeting the inflammatory pathway as a therapeutic tool for major depression. Neuroimmunomodulation. 2014;21(2-3):131-9. 
Table 1. Classes of drugs and their effects on sleep

\begin{tabular}{|c|c|c|c|c|c|}
\hline Drug Class & $\begin{array}{l}\text { Sleep } \\
\text { Continuity }\end{array}$ & $\begin{array}{l}\text { Slow-wave } \\
\text { Sleep (SWS) }\end{array}$ & $\begin{array}{l}\text { REM } \\
\text { latency }\end{array}$ & $\begin{array}{l}\text { REM } \\
\text { sleep }\end{array}$ & Mechanism of action regarding sleep \\
\hline $\begin{array}{l}\text { SSRI (e.g. fluoxetine, } \\
\text { escitalopram, paroxetine, } \\
\text { sertraline) }\end{array}$ & $-/ 0$ & $0 /+$ & + & - & Selective inhibition of serotonin reuptake \\
\hline $\begin{array}{l}\text { SNRI and NRI (e.g., } \\
\text { venlafaxine, duloxetine, } \\
\text { reboxetine) }\end{array}$ & - & $0 /+$ & + & - & Inhibition of serotonin and norepinephrine reuptake \\
\hline $\begin{array}{l}\text { MAOI (e.g., tranylcypromine, } \\
\text { moclobemide) }\end{array}$ & $-/ 0$ & $?$ & + & - & Inhibition of monoamine oxidase enzyme \\
\hline $\begin{array}{l}\text { Sedative TCA (e.g., } \\
\text { amitriptyline, doxepin, } \\
\text { trimipramine) }\end{array}$ & + & + & + & & $\begin{array}{l}\text { Inhibition of serotonin and norepinephrine } \\
\text { reuptake, antihistaminergic effect }\end{array}$ \\
\hline $\begin{array}{l}\text { Activating TCA (e.g., } \\
\text { imipramine, desipramine) }\end{array}$ & - & - & + & - & Inhibition of serotonin and norepinephrine reuptake \\
\hline Agomelatine & + & + & & 0 & $\begin{array}{l}\text { Agonism at melatonin } \mathrm{M} 1 \text { and } \mathrm{M} 2 \text { receptors, } \\
\text { antagonism at serotonergic 5-HT2C receptors }\end{array}$ \\
\hline Bupropion & $0 /-$ & $0 /+$ & $0 /-$ & $0 /+$ & $\begin{array}{l}\text { Inhibition of dopamine and norepinephrine } \\
\text { reuptake }\end{array}$ \\
\hline $\begin{array}{l}\text { Sedative antidepressants (e.g., } \\
\text { mirtazapine, trazodone) }\end{array}$ & + & + & 0 & 0 & $\begin{array}{l}\text { antagonism at serotonergic 5-HT2A receptors, } \\
\text { antihistaminergic effect }\end{array}$ \\
\hline Vortioxetine & $0 /-$ & & + & - & $\begin{array}{l}\text { Inhibition of serotonin reuptake, modulation of } \\
\text { serotonergic receptors activity }\end{array}$ \\
\hline
\end{tabular}

SSRI selective serotonin reuptake inhibitors, SNRI serotonin norepinephrine reuptake inhibitors, NRI norepinephrine reuptake inhibitors, TCA tricyclic antidepressants, MAOI monoamine oxidase inhibitors, “+” increase, “_“" decrease, "0” no effect, “?” unknown 
Table 2. Limitations of the literature in the approach of insomnia in MDD.

\begin{tabular}{|c|c|c|c|}
\hline $\begin{array}{l}\text { Group of } \\
\text { potential biases }\end{array}$ & Limitations & Example & Strategies to address \\
\hline \multirow[t]{2}{*}{ Selection } & $\begin{array}{l}\text { Few data on } \\
\text { subpopulations }\end{array}$ & $\begin{array}{l}\text { Most studies include } \\
\text { general population, and } \\
\text { few approached } \\
\text { children and } \\
\text { adolescents, pregnant } \\
\text { women or elderly. }\end{array}$ & $\begin{array}{l}\text { Stratification of } \\
\text { samples. }\end{array}$ \\
\hline & $\begin{array}{l}\text { Samples not } \\
\text { representative of the } \\
\text { populations with } \\
\text { insomnia and MDD in } \\
\text { clinical practice }\end{array}$ & $\begin{array}{l}\text { Studies not specifically } \\
\text { designed to assess } \\
\text { insomnia in MDD }\end{array}$ & $\begin{array}{l}\text { Design studies } \\
\text { specifically targeting } \\
\text { insomnia in MDD (not } \\
\text { only post-hoc analysis) }\end{array}$ \\
\hline \multirow[t]{2}{*}{$\begin{array}{l}\text { Outcomes } \\
\text { assessment }\end{array}$} & $\begin{array}{l}\text { Indirect assessment of } \\
\text { insomnia }\end{array}$ & $\begin{array}{l}\text { Extract data about sleep } \\
\text { from depression scales } \\
\text { (e.g. Ham-D, MADR) }\end{array}$ & $\begin{array}{l}\text { Inclusion of specific } \\
\text { and reliable } \\
\text { questionnaires }\end{array}$ \\
\hline & $\begin{array}{l}\text { Subjective assessment } \\
\text { of insomnia severity }\end{array}$ & $\begin{array}{l}\text { Most studies do not use } \\
\text { objective (and } \\
\text { potentially expensive) } \\
\text { methods to assess } \\
\text { insomnia and sleep } \\
\text { architecture }\end{array}$ & $\begin{array}{l}\text { Use of wearable } \\
\text { devices }\end{array}$ \\
\hline \multirow[t]{2}{*}{ Confounders } & $\begin{array}{l}\text { Psychiatric } \\
\text { comorbidities }\end{array}$ & $\begin{array}{l}\text { Incomplete } \\
\text { consideration of biases } \\
\text { such as anxiety, } \\
\text { substance abuse and } \\
\text { environmental stress } \\
\end{array}$ & \multirow[t]{2}{*}{$\begin{array}{l}\text { Sample size large } \\
\text { enough to control for } \\
\text { potential confounders. } \\
\text { Careful definition of } \\
\text { inclusion/exclusion } \\
\text { criteria. }\end{array}$} \\
\hline & $\begin{array}{l}\text { General medical } \\
\text { comorbidities }\end{array}$ & $\begin{array}{l}\text { Incomplete } \\
\text { consideration of factors } \\
\text { such as Body Mass } \\
\text { Index, sleep } \\
\text { disturbances and other } \\
\text { medical conditions and } \\
\text { general medications }\end{array}$ & \\
\hline
\end{tabular}


Figure 1. Schematic representation of the clinical correlates of insomnia in MDD.

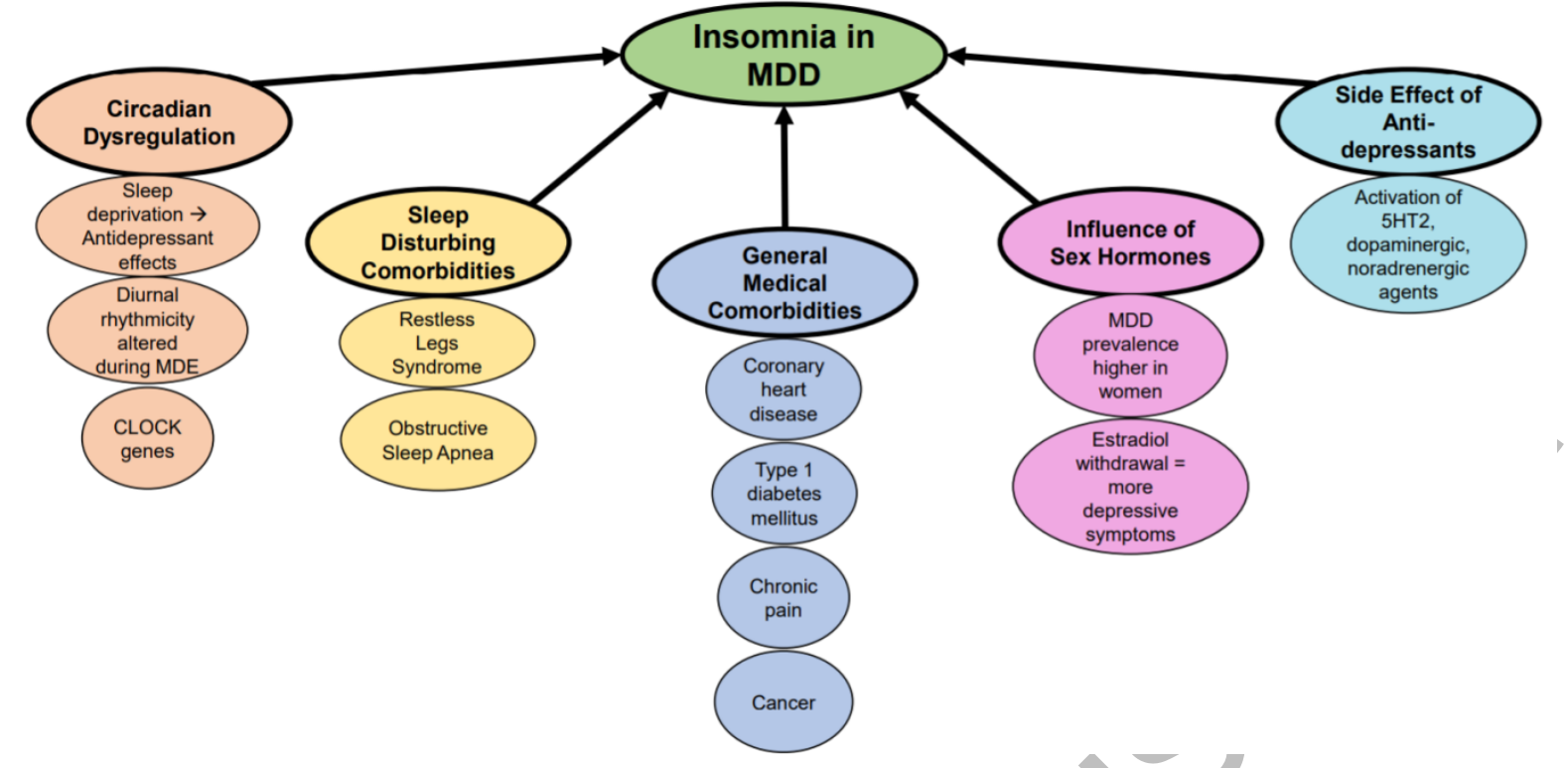

